\title{
Análise dos fatores que influenciaram na concentração de material particulado na área urbana de Rondonópolis (MT)
}

A sazonalidade do período de estiagem no Centro-Oeste brasileiro apresenta peculiaridades, quanto ao potencial de danos ao meio ambiente e a saúde human por meio da poluição atmosférica. Este trabalho tem como objetivo analisar as concentrações de material particulado (MP1, MP2,5 e MP10) na área urbana do município de Rondonópolis (MT), relacionando às variáveis meteorológicas e focos de calor, no período entre os meses de agosto a setembro de 2017 . Os dados meteorológicos são provenientes do Instituto Nacional de Meteorologia (INMET). Os dados de focos de calor foram junto ao Instituto Nacional de Pesquisas Espaciais (INPE). Em campo, coletou-se os dados de poluição atmosférica, utilizando a medição de material particulado - MP, MP1, MP2,5 e MP10, por meio do aparelho Aeroqual modelo AQM10 instalado na Secretaria do Meio Ambiente (SEMA) do município. Utilizou-se a análise estatística como a correlação de Kendal em $5 \%$ de significância, que posteriormente foi ajustado ao modelo de regressão Gamma, pertencente à classe dos Modelos Lineares Generalizados (MLG), com nível de significância de $5 \%(\mathrm{p}<0,05)$. Foi aplicada a densidade Kernel, e criado um mapa de focos de calor. As variáveis climáticas, temperatura, umidade relativa do ar e precipitação exercem influência nas concentrações de material particulado $\left(\mathrm{MP}_{1}, \mathrm{MP}_{2,5}\right.$ e $\left.\mathrm{MP}_{10}\right)$ veiculados na atmosfera no município de Rondonópolis, região sul de Mato Grosso.

Palavras-chave: Poluição atmosférica; Qualidade do ar; Queimadas.

\section{Analysis of the factors that influenced the concentration of particulate matter in the urban area of Rondonópolis (MT)}

\begin{abstract}
The seasonality of the drought period in the Brazilian Midwest presents peculiarities regarding the potential of damage to the environment and human health through atmospheric pollution. This paper aims to analyze the concentrations of particulate matter (MP1, MP2.5 and MP10) in the urban area of the municipality of Rondonópolis (MT), relating to the meteorological variables and hot flashes, from August to September 2017. Weather data comes from the National Institute of Meteorology (INMET). The data from heat sources were obtained from the National Institute for Space Research (INPE). In the field, air pollution data were collected using the measurement of particulate matter - MP, MP1, MP2.5 and MP10, by means of the Aeroqual model AQM10 device installed at the Municipal Secretariat of the Environment (SEMA). Statistical analysis was used as the $5 \%$ significance Kendall correlation, which was later adjusted to the Gamma regression model, belonging to the Generalized Linear Models (MLG) class, with a significance level of $5 \%(p<0,05)$. Kernel density was applied, and a map of heat foci was created. Climatic variables, temperature, relative humidity and precipitation influence the concentrations of particulate matter $\left(\mathrm{MP}_{1}, \mathrm{MP}_{2}, 5\right.$ and $\left.\mathrm{MP}_{10}\right)$ in the atmosphere of Rondonópolis, southern Mato Grosso region.
\end{abstract}

Keywords: Atmospheric pollution; Air quality; Burned out.

Topic: Sistemas de Gestão Ambiental

Reviewed anonymously in the process of blind peer
Received: $\mathbf{2 4 / 1 0 / 2 0 1 8}$

Approved: $\mathbf{2 5 / 1 1 / 2 0 1 8}$
Cauê Felipe Pimentel (iD

Universidade Federal de Mato Grosso, Brasil http://lattes.cnpq.br/8656747201313407

http://orcid.org/0000-0002-2090-8695

cauefp@hotmail.com

Dhonatan Diego Pessi (i)

Universidade Federal de Mato Grosso, Brasil

http://lattes.cnpq.br/3571683471770302

http://orcid.org/0000-0003-0781-785X

dhonatan.pessi@gmail.com

Domingos Sávio Barbosa (iD

Universidade Federal de Mato Grosso, Brasil

http://lattes.cnpq.br/6896725721269796

http://orcid.org/0000-0001-6793-0956

domingosbar@gmail.com

\author{
Normandes Matos da Silva \\ Universidade Federal de Mato Grosso, Brasil \\ http://lattes.cnpq.br/2644207249389541 \\ normandes32@gmail.com \\ Ricardo Alves de Olinda (iD) \\ Universidade Estadual da Paraíba, Brasil \\ http://lattes.cnpq.br/77672223263366578 \\ http://orcid.org/0000-0002-0509-8428 \\ ricardo.estat@yahoo.com.br
}

Referencing this:

PIMENTEL, C. F.; PESSI, D. D.; BARBOSA, D. S.; SILVA, N. M.; OLINDA, R. A.. Análise dos fatores que influenciaram na concentração de material particulado na área urbana de Rondonópolis (MT). Revista IberoAmericana de Ciências Ambientais, v.9, n.8, p.343-358, 2018. DOI: http://doi.org/10.6008/CBPC2179-6858.2018.008.0029 


\section{INTRODUÇÃO}

Nesse último século (XX), a dispersão de poluentes pelo ar teve um aumento significativo, e vem sendo motivo de preocupações entre a sociedade e a comunidade técnico-científica (VELLOSO, 2007), devido à qualidade da saúde humana e do ambiente. Esse efeito pode ocorrer por consequência de processos naturais como queimadas, atividades vulcânicas, e por fatores antrópicos.

O município de Rondonópolis (MT) está inserido no bioma Cerrado, com duas estações climáticas bem definidas: a chuvosa e a seca. A economia local é principalmente agricultura e pecuária com extensas áreas de pastagem. Durante os meses de estiagem que compreendem de maio a setembro, a umidade relativa do ar cai para menos de $10 \%$. Durante esse período ocorrem queimadas, principalmente na zona rural, particularmente em locais com cobertura vegetal seca.

As queimadas contribuem para a poluição do ar por liberarem grandes concentrações de gases e partículas na atmosfera durante o período de estiagem. O estado de Mato Grosso durante a seca e com a queima da biomassa, contribui de maneira significativa com a poluição atmosférica, pois libera altos índices de gases e material particulado (IGNOTTI et al., 2007).

Com a queima da biomassa ocorre a liberação de muitos poluentes, como o monóxido e dióxido de carbono (CO e $\mathrm{CO} 2$ ), dióxido de enxofre ( $\mathrm{SO} 2)$, metano ( $\mathrm{CH} 4)$, óxido de nitrogênio (NOX), vapor d'água (H2O), dióxido de nitrogênio (NO2). Com o processo de queima ocorre a formação de partículas e a quantidade de partículas é proporcional à quantidade de fumaça (ROCHA et al., 2004).

Conforme Resolução CONAMA n003/90, a poluição atmosférica pode ser qualquer forma de matéria ou energia com intensidade e em quantidade, concentração tempo ou características em desacordo com os níveis estabelecidos, tornando o ar impróprio, nocivo ou ofensivo à saúde humana; danosos à fauna e flora; prejudicial à segurança ao uso e gozo da propriedade e às atividades normais da comunidade (CONAMA, 1990).

Os padrões de qualidade do ar estabelecidos pela Resolução CONAMA n003/90, define legalmente o limite máximo para a concentração de poluentes na atmosfera de maneira que garanta a proteção da saúde humana e ambiental. Os padrões estão divididos em dois tipos: primários e secundários. Os primários são aqueles que se houver concentrações acima do permitido, irão afetar a saúde da população. Os padrões secundários são as concentrações de poluentes atmosféricos abaixo do que se prevê o mínimo efeito adverso sobre o bem-estar da população, assim como o mínimo dano à fauna e flora, aos materiais e ao meio ambiente (CONAMA, 1990).

Este trabalho visou analisar as concentrações de material particulado $\left(\mathrm{MP}_{1}, \mathrm{MP}_{2,5}\right.$ e $\left.\mathrm{MP}_{10}\right)$ na área urbana de Rondonópolis relacionando as variáveis meteorológicas e os focos de queimadas, entre os meses de agosto de 2017 a setembro de 2017, para subsidiar medidas que garantam a qualidade do ar na área de estudo e seu entorno. 


\section{METODOLOGIA}

\section{Descrição da Área de Estudo}

Para o desenvolvimento deste estudo utilizou-se a área urbana do município de Rondonópolis, região

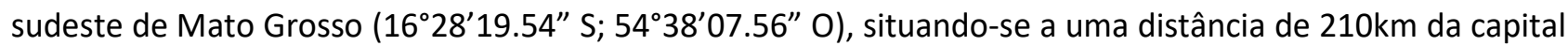
Cuiabá. O município de Rondonópolis possui uma área total de $4.165 \mathrm{~km}^{2}$, e sua área urbana possui $129,2 \mathrm{~km}^{2}$ (figura 1).

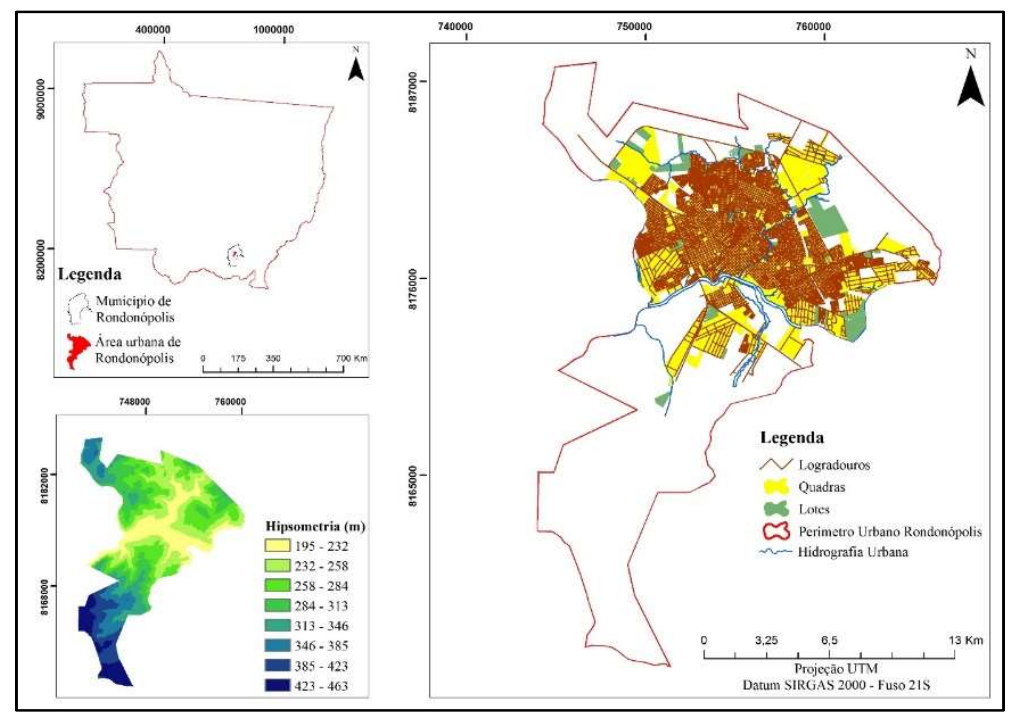

Figura 1: Mapa de localização e de hipsometria da área de estudo caracterizada como a área urbana de Rondonópolis (MT).

A vegetação existente na região está dividida em grupos fitofisionomicamente diferentes, destacando-se o Cerradão, Cerrados, Formação Savânica associada a vertentes e Floresta Estacional. Os fragmentos de vegetação presentes na área de estudo são classificados como mata ciliar, as quais são consideradas semidecíduas com composição florística típica e com diferentes graus de caducifólia na estação seca. Os portes podem variar de 20 a 25 metros, com alguns poucos indivíduos emergentes alcançando 30 metros ou mais (RIBEIRO et al., 1998).

O clima é considerado tropical para a região de Rondonópolis, consistindo em uma temperatura média anual de $25^{\circ} \mathrm{C}$, sendo a média das máximas de $32,6^{\circ} \mathrm{C}$ e a média das mínimas $18,6^{\circ} \mathrm{C}$. Os meses de setembro até outubro são caracterizados como sendo os mais quentes com médias acima de $26^{\circ} \mathrm{C}$, e os meses de junho e julho apresentam as menores médias com $21,9^{\circ} \mathrm{C}$ e $22,3^{\circ} \mathrm{C}$, respectivamente. As estações são bem definidas, sendo que a estação chuvosa compreende pelos meses de outubro a abril e os totais acumulados de chuva nessa estação ficam em média de $1300 \mathrm{~mm}$. Já a estação seca se inicia em maio e estende-se até o mês de setembro, com uma duração em torno de 5 meses com totais acumulados de chuva ficando em torno de 130mm (SETTE, 1996; TRASSI, 2015).

A área urbana de Rondonópolis está localizada no setor oeste/sudoeste da bacia do Rio Vermelho. Essa região apresenta terrenos com altitudes que variam de $210 \mathrm{~m}$ acima do nível do mar nas proximidades da confluência do rio Vermelho e córrego Arareau até cerca de $320 \mathrm{~m}$ nas regiões mais elevadas no setor noroeste e $290 \mathrm{~m}$ nos pontos mais altos do setor leste. Os solos são predominantemente Latossolo Vermelho 
- Escuro Álico, Latossolo Vermelho - Amarelo Álico, Podzólico Vermelho - Amarelo Eutrófico, Cambissolo Distrófico e Areias Quartzosas Álicas (WERLANG, 1997; TRASSI, 2015).

\section{Aquisição, seleção e organização dos dados}

Os dados de material particulado atmosféricos $\mathrm{MP}_{1,0}, \mathrm{MP}_{2,5}$ e $\mathrm{MP}_{10}$ foram coletados do banco de dados de um equipamento de marca Aeroqual modelo AQM10 instalado na área urbana, na Secretaria Municipal de Meio Ambiente de Rondonópolis. O sistema detecta duplo comprimento de onda fornecendo o volume médio de amostras de particulados, recolhe informações continuamente a cada 1 minuto de materiais particulados $\mathrm{MP}_{1,0}, \mathrm{MP}_{2,5}$ e $\mathrm{MP}_{10}$ armazenando-os num banco de dados local. Foi utilizado um período de trinta dias, de 14 de agosto de 2017 a 12 de setembro de 2017, para a coleta dos dados, considerando que neste período houve aumento do número de queimadas nas proximidades do perímetro urbano dispersando uma grande quantidade de material particulado pelo ar.

As informações meteorológicas referentes ao mesmo período de análise foram coletadas no site do Instituto Nacional de Meteorologia (INMET) da estação Rondonópolis-A907 número 86728 instalada nas coordenadas latitude $-16.462419^{\circ}$; longitude $-54.580151^{\circ}$. Os dados de focos de calor foram obtidos do processamento diário das imagens termais do sensor AVHRR, a bordo dos satélites NOAA-12 e NOAA-15.

Os dados geoespaciais utilizados pelo presente trabalho foram adquiridos de forma gratuita por meio da rede mundial de computadores em sítios eletrônicos de instituições governamentais, que disponibilizam informações geoespaciais relacionadas diretamente com o recorte territorial de interesse para este estudo. Para o presente estudo foi adotado o Sistema de Coordenadas Geográficas e Datum SIRGAS 2000. A malha municipal foi adquirida no Instituto Brasileiro de Geografia e Estatística (IBGE). Já os vetores de importância biológica e unidades de conservação, foi consultado o site do Ministério do Meio Ambiente (MMA) que disponibiliza em shapefile.

A tabulação dos dados meteorológicos temperatura (instante, máxima e mínima), umidade relativa do ar (instante, máxima e mínima), velocidade do vento e precipitação, os dados de poluição atmosférica, material particulado $\mathrm{MP}_{1,0} \mathrm{MP}_{2,5} \mathrm{MP}_{10}$, e focos de queimadas ocorreram utilizando o software $\mathrm{Exce}^{\circledR}$, sendo realizada a análise descritiva dos dados por meio do software $\mathrm{R}$, por meio das médias diárias das variáveis dependentes concentração de material particulado $\left(\mathrm{MP}_{1,0} \mathrm{MP}_{2,5} \mathrm{MP}_{10}\right)$ e das médias diárias das variáveis independentes meteorológicas (temperatura (instante, máxima e mínima), umidade relativa do ar (instante, máxima e mínima), velocidade do vento e precipitação) foi obtida pela medida de tendência central (média e mediana) e de dispersão (desvio padrão, assimetria, variância, 1ำ quantil e 3ㅇquantil).

A correlação de Kendall, foi utilizada tendo em vista que a maioria de suas variáveis não seguiram um comportamento normal e foram medidas ao longo do tempo, caracterizando assim, uma estrutura de autocorrelação temporal (séries temporais). Para testar se as correlações foram significativas, utilizou-se o a correlação de Kendall em $5 \%$ de significância: $S=\sum_{-}\{i<j\}(\operatorname{sign}(x[j]-x[i]) * \operatorname{sign}(y[j]-y[i]))$ e $D=n(n-1) / 2$. Assim, S é chamado de pontuação e $D$, o denominador, é o valor máximo possível de S. Quando há laços, a fórmula para D é mais complicada (KENDALL, 1974) e essa fórmula geral para laços em ambos rankings é apresentada 
nesta função. Desta forma, calcula-se o a correlação da classificação de Kendall e o valor - $p$ em um teste de dois lados de H0: $x$ e y são independentes.

Foi ajustado um modelo de regressão Gamma pertencente à classe dos Modelos Lineares Generalizados (MLG), adotando-se um nível de significância de 5\% $(p<0,05)$. A vantagem do uso dos MLGs na análise de dados positivos assimétricos deve-se ao fato de evitarmos transformações na variável dependente com a finalidade de encontrar normalidade e homocedasticidade dos erros, visto que as transformações podem não ser adequadas em determinadas situações e, portanto, os dados podem não se adequar aos pressupostos do modelo linear normal. Desse modo, os modelos de regressão Gamma são úteis e bastante utilizados na modelagem de dados com tal comportamento assimétrico.

Para avaliar a adequação do modelo estatístico proposto para descrever as observações, foram verificadas a normalidade e independência dos erros. Com este procedimento, estar-se-á buscando condições teóricas para a realização das análises estatísticas via técnicas univariadas. Os dados geoespaciais de focos de calor foram organizados por dia e em uma única base de dados, com a finalidade de facilitar a visualização das informações acumuladas e manipulação e edição de sua tabela de atributos.

Após a sobreposição dos dados dos focos de calor e limites territoriais, dados matriciais de densidade de focos de calor acumulado para o período de estudo foram gerados por meio do algoritmo estimador de densidade de Kernel presente na extensão Spatial Analyst Tools/Density/Point Density do software ArcGis 10.5. O estimador de densidade Kernel desenha uma vizinhança circular ao redor da cada ponto da amostra, correspondendo ao raio de influência, e então é aplicada uma função matemática de 1, na posição do ponto, a 0 , na fronteira da vizinhança.

O valor para a célula é a soma dos valores Kernel sobrepostos, e divididos pela área de cada raio de pesquisa (SILVERMAN, 1986). O objetivo da análise de Kernel é obter estimativa suavizada da densidade de focos de calor por unidade de área. Essa contagem é ponderada pela distância de cada evento ao ponto de referência dentro de um dado raio, uma propriedade de relevância para a análise da tendência de um processo estocástico espacial (SILVA et al., 2009).

Após a aplicação da densidade Kernel, foi criado um mapa de focos de calor classificado com níveis de densidade que variam de acordo com um gradiente de cores sendo que: Vermelho é caracterizado por densidade muita alta até a cor Azul que é de densidade muito baixa. Adicionalmente, foram também cruzados os dados de calor com as áreas de importância biológica e áreas prioritárias para conservação para identificar se as zonas com maior densidade podem ser associadas a essas áreas. A partir dos dados climatológicos coletados no site do INMET, foram organizados dados da direção ( $\left(^{\circ}\right)$ e da velocidade do vento $\left(\mathrm{m} . \mathrm{s}^{-1}\right)$ para o período de estudo. Por meio destes dados, foram elaborados histogramas e rosas dos ventos com o auxílio do programa WRPLOT. 


\section{RESULTADOS E DISCUSSÃO}

\section{Análise meteorológica}

Os resultados dos valores acumulados para as variáveis de precipitação, velocidade do vento, umidade relativa e temperatura, encontram-se na figura 2. A força e velocidade do vento é uma variante significativa que se deve levar em conta, pois possui um papel importante na dispersão dos poluentes. As maiores velocidades do vento foram registradas entre os dias 16/08/2017 a 25/08/2017 com velocidades variando de $2 \mathrm{~m} \cdot \mathrm{s}^{-1}$ a $1,3 \mathrm{~m} \cdot \mathrm{s}^{-1}$ (Figura $2 \mathrm{~A}$ ).

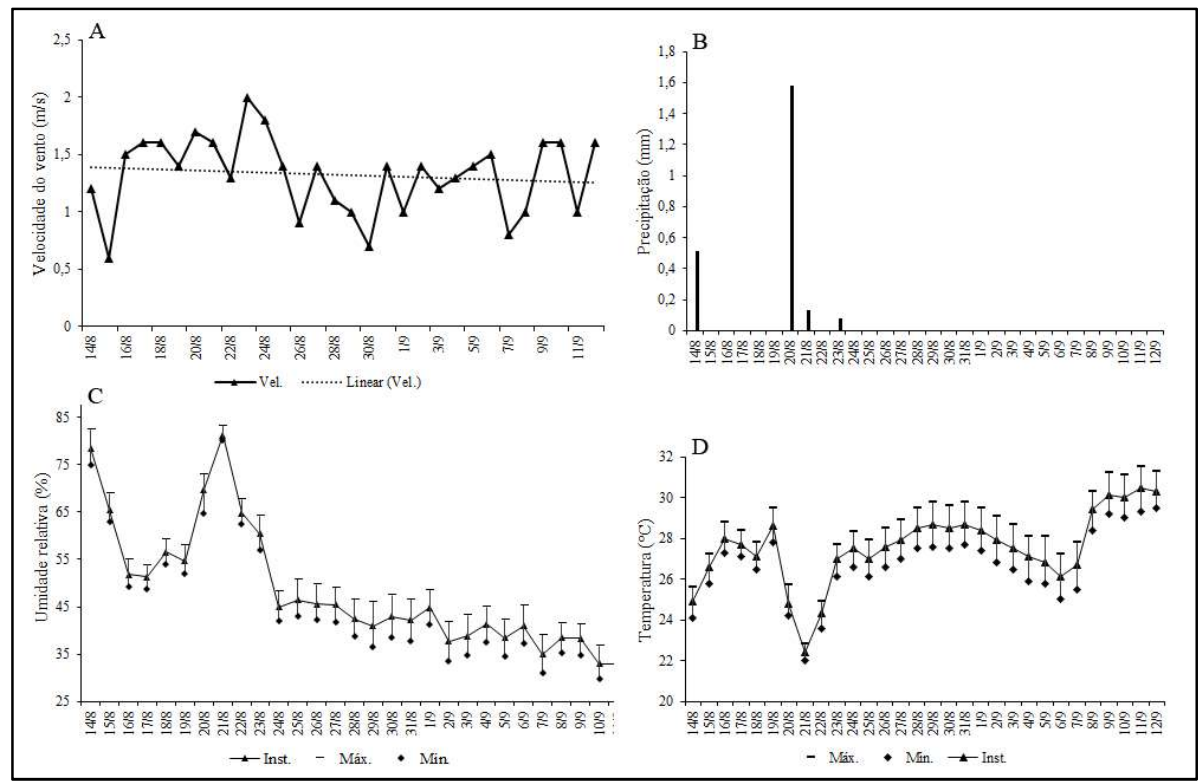

Figura 2: Gráficos com as médias meteorológicas, da velocidade do vento (A), de precipitação (B), com as máximas e mínimas dos dados de umidade relativa do ar (C), e de temperatura (D).

A baixa velocidade do vento combinado com a inversão da temperatura e do vento tende a manter as concentrações de poluentes atmosféricos com valores altos devido a limitação da dispersão dos poluentes (ZHAO, 2014), à medida que a velocidade do vento aumenta para a faixa de $2 \mathrm{~m} \cdot \mathrm{s}^{-1}$, a diferença entre as concentrações de poluentes atmosféricos tende a diminuir, pois o vento mais intenso promove maior mistura. Além do mais, a velocidade do vento pode, portanto, ter relações complexas com a extensão espacial, devido às vezes possuir um efeito sobre a diluição inicial, dispersão vertical, e coagulação de partículas ultrafinas (ZHOU et al., 2007).

Durante o período do ano em que há mudanças bruscas de temperaturas e estiagem prolongada, como é o caso do Cerrado, é considerado um fator de risco para problemas respiratórios (CARNESECA et al., 2012), agravado pela inalação de fumaça e poluentes liberados pelas queimadas. Segundo as investigações de Jallad et al. (2013), existe uma correlação entre os efeitos de temperatura sobre a formação de novas partículas através de processos de conversão de gás em partículas.

Os dias que ocorreram chuvas foi 14/8, 20/8, 21/8 e 23/8 com máxima de 1,58mm no dia 20/8 e mínima de $0,08 \mathrm{~mm}$ no dia 23/8. Durantes os outros dias não houve chuvas. A chuva tem um papel importante na diminuição da concentração de poluentes atmosféricos, uma vez que o vapor d'água absorve as partículas suspensas no ar e por transferência do ar para o solo através da chuva (figura 2B). Trabalhos realizados por 
Carneseca et al. (2012), demonstram que quando há baixos níveis de pluviometria os índices de $\mathrm{MP}_{10}$ sofrem um alto aumento, o que indica que quantidade de chuvas está associado à quantidade de material particulado na atmosfera.

A umidade relativa do ar teve máximas de $81,2 \%$ no dia $21 / 8$ até uma mínima de $32,8 \%$ no dia $11 / 9$ (Figura 2C). Entre os dias 14 e 23 de agosto, houve percentuais altos devido às chuvas do dia 14 e 20 de agosto. As mínimas estão registradas entre os dias $07 / 9$ a 11/9 devido que no mês de setembro há os menores registros de umidade relativa do ar devido ser o mês mais seco do período de estiagem para a região de Cerrado do sul mato-grossense. O baixo percentual de umidade do ar está relacionado a altos valores de poluição do ar, sendo mais bem visualizado no período de estiagem, que no Cerrado está compreendido entre os meses de maio a setembro. Mas trabalhos como de Li et al. (2010) demonstram que quando a umidade relativa do ar está alta, existe um aumento significativo de aerossóis higroscópicos os quais podem induzir no aumento da concentração de PM e no espalhamento desses materiais.

As temperaturas instantes variaram de máximas de $30,5^{\circ} \mathrm{C}$ no dia $11 / 09 / 2017$ a mínimas de $22,4^{\circ} \mathrm{C}$ no dia $21 / 08 / 2017$. Entre os dias 20/08/2017 a 22/08/2017 foi registrado as menores temperaturas devido às chuvas que ocorreram nestes dias. A temperatura média para o período estudado foi de $27,6^{\circ} \mathrm{C}$ (figura 2D). Foram registrados ao todo 451 focos de queimadas durante o período de estudo. A maior intensidade de focos foi entre os dias 31/08/2017 a 06/09/2017 sendo que a maior quantidade de focos se deu no dia 03/09/2017 com 109 focos de queimadas (Figura 3).



Figura 3: Distribuição do número de focos de queimadas pelo período analisado.

O que se percebe é que durante os dias de maior quantidade de focos de queimadas, as temperaturas estavam em seu maior pico, variando de $28,7^{\circ} \mathrm{C}$ a $26,1^{\circ} \mathrm{C}$, e a umidade relativa do ar em constante queda $(37,7 \%$ a $31,1 \%)$ como mostra os gráficos nas Figuras 2 e 1, respectivamente. Essas variações de baixa umidade relativa do ar com a elevada temperatura foram contribuintes para a maior intensidade de focos de queimadas no período analisado.

A emissão de material particulado no Estado de Mato Grosso ocorre principalmente da queima de biomassa que é entendido entre os meses de maio a setembro, meses em que há poucas chuvas (IGNOTTI et al., 2007), e também essas emissões depende muito das condições ambientais, climáticas e principalmente da velocidade do vento (RIBEIRO et al., 2002). 
Segundo estudos de Abreu et al. (2016), no Estado de Mato Grosso, entre os anos de 2005 e 2010, a maior concentração de focos de queimada foram encontrados no período de seca, que segundo o autor não ocorrem raios nessa região levantando a hipótese de que esses focos sejam de origem antrópica. Adicionalmente, a figura 4B demonstra que a maior intensidade de focos de queimadas ocorreram próximas ao perímetro urbano da cidade de Rondonópolis e que inclusive a sua maior abrangência está localizada dentro de áreas de importância biológica e para conservação como é o caso da reserva indígena do Tadarimana e outras áreas de corredor ecológico entre essa reserva e a Área de Preservação Permanente do rio Vermelho (figura 4A)

Analisando o mapa de densidade, percebe-se que a extensão 'Alta' compreendida nas cores de um vermelho até o amarelo, está em sua maior quantidade inserida dentro da reserva indígena, na qual foi visualizado o maior número de focos de queimada. Conforme Abreu et al. (2016), a ocorrência de focos de queimadas em terras indígenas de Xavantes e Bororos no Estado de Mato Grosso é mais bem visualizado no período de estiagem, além de que essas áreas possuem baixa porcentagem de desmatamento quando cruzado os dados de focos de calor com os de desmatamento. Ainda nesse sentido, os mesmos autores destacam que a maioria dos focos de queimada no período de estiagem não estão relacionados com a ocorrência de raios, mas há uma forte hipótese de que esses focos de calor sejam de origem antrópica (ABREU et al., 2016).

É necessário que haja mais estudos no sentido de avaliar melhor o efeito do fogo em terras indígenas do Mato Grosso (PRADA et al., 2004), procurando propor estratégias relacionadas ao manejo do uso do fogo. Conforme elucida Melo (2007), é comum a prática de queimadas em reservas indígenas de Xavantes e Bororos devido às atividades de caça com o fogo, sugerindo que no caso de Rondonópolis a maior incidência de queimadas na terra indígenas dos Bororos pode estar relacionada às atividades antrópicas de caça animal (ABREU et al., 2016). Além disso, as queimadas podem também ser intencionais, principalmente em pastos às margens da aldeia, proveniente de bitucas de cigarros, lixos altamente voláteis que influenciam no início de queimadas.

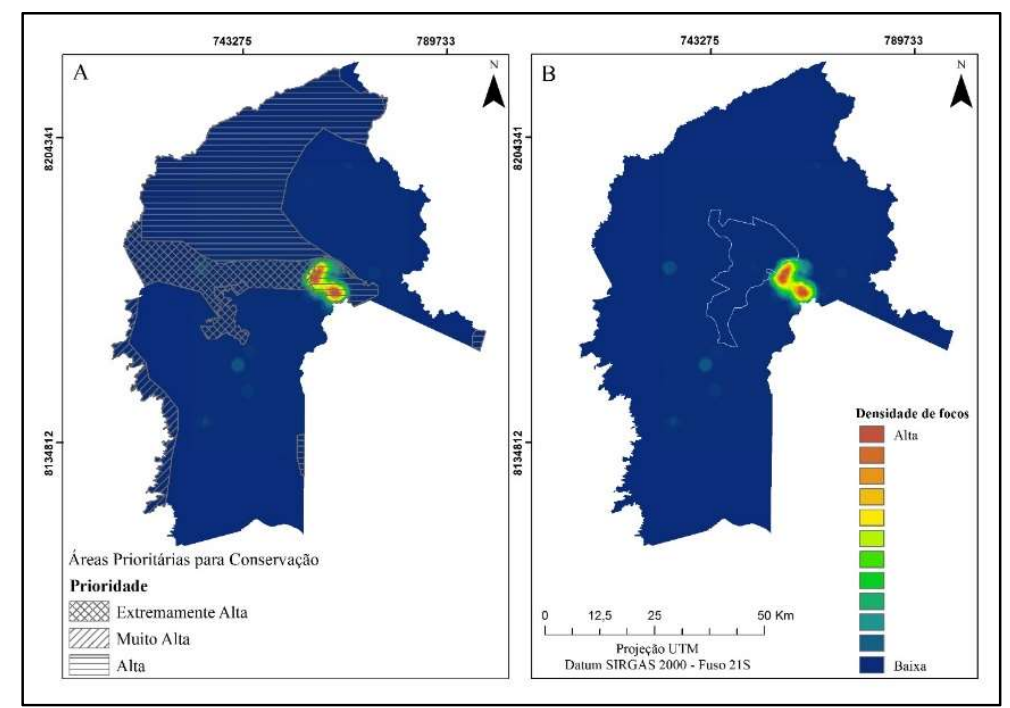

Figura 4: Distribuição espacial dos focos de queimada, de acordo a prioridade das áreas de conservação e a densidade dos focos. 
Nota-se que a dispersão dos poluentes devido aos focos de queimadas foi grande, pois como mostra a rosa do vento (figura 5) durante os dias em que houve maior quantidade de focos de queimadas, o vento estava vindo do leste com uma média de velocidade de $1,31 \mathrm{~m} \cdot \mathrm{s}^{-1}$, região onde se encontravam a maior quantidade de focos de queimadas conforme figura 7. Isso corroborou com os altos índices de material particulado analisados neste período de estudo.



Figura 5: Rosa dos ventos com as direções de maiores proporções das rajadas de vento e força.

\section{Resultados e análise dos Poluentes Atmosféricos}

O Material Particulado (MP) evidenciado pela coleta dos dados apresenta-se como um fator relevante para o estudo no município de Rondonópolis (MT), devido a ser um município de grande densidade demográfica e estar localizado em uma região que sofre períodos de secas prolongado, somado ao fato descrito dos múltiplos focos de queimadas em áreas próximas ao seu perímetro urbano.

Observa-se na figura 6 a distribuição das médias diárias de material particulado, tendo o dia 21/08/2017 com a menor incidência de material particulado $\left(\mathrm{MP}_{1} 4,17 \mu \mathrm{g} / \mathrm{m}^{3} ; \mathrm{MP}_{2,5} 6,16 \mu \mathrm{g} / \mathrm{m}^{3}\right.$ e $\mathrm{MP}_{10}$ $9,49 \mu \mathrm{g} / \mathrm{m}^{3}$ ), já no dia 06/09/2017 obteve-se a maior incidência de material particulado na atmosfera (MP1

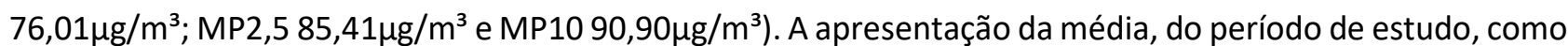
$\left(\mathrm{MP}_{1} 25,52 \mu \mathrm{g} / \mathrm{m}^{3} ; \mathrm{MP}_{2,5} 29,84 \mu \mathrm{g} / \mathrm{m}^{3}\right.$ e $\left.\mathrm{MP}_{10} 34,45 \mu \mathrm{g} / \mathrm{m}^{3}\right)$ possibilita uma avaliação com base nas referências nacionais e internacionais acerca da qualidade da poluição atmosférica.

Conforme a resolução CONAMA 003/1990 o material particulado é inserido na classificação partículas inaláveis $(<10 \mu \mathrm{m})$ que apresenta como padrão primário e secundário a concentração média aritmética anual de $50 \mu \mathrm{g} / \mathrm{m}^{3}$ de ar e a concentração média de 24 (vinte e quatro) horas de $150 \mu \mathrm{g} / \mathrm{m}^{3} \mathrm{de}$ ar, que não deve ser excedida mais de uma vez por ano.

Em uma perspectiva mundial, o relatório Poluição Ambiental do Ar publicado pela Organização Mundial de Saúde (WHO, 2016), apresenta considerações de diferentes valores relacionados ao material 
particulado encontradas na resolução 003 da CONAMA (1990) destacando a existência de impactos a saúde humana com valores superiores para o $\mathrm{MP}_{2,5}$ em sua média anual de $10 \mu \mathrm{g} / \mathrm{m}^{3}$ e média de 24 horas de 25 $\mu \mathrm{g} / \mathrm{m}^{3}$, já o $\mathrm{MP}_{10}$ com média anual de $20 \mu \mathrm{g} / \mathrm{m}^{3}$ e média de 24 horas de $50 \mu \mathrm{g} / \mathrm{m}^{3}$.

A presença da maior intensidade de focos de queimadas, representado pela Figura 3, é associada ao aumento da emissão de material particulado, figura 6, com maior representatividade ao dia 06/09/2017 que evidencia o pico de emissão de material particulado $\left(\mathrm{MP}_{2,5} 85,41 \mu \mathrm{g} / \mathrm{m}^{3}\right.$ e $\left.\mathrm{MP}_{10} 90,90 \mu \mathrm{g} / \mathrm{m}^{3}\right)$ quando comparado com a média apresentada pela OMS (2016) apresentam valores elevados e com potenciais consequências a saúde humana. Enquanto a resolução CONAMA 003 (1990) os valores acima apresentados ainda são considerados dentro da permissibilidade.

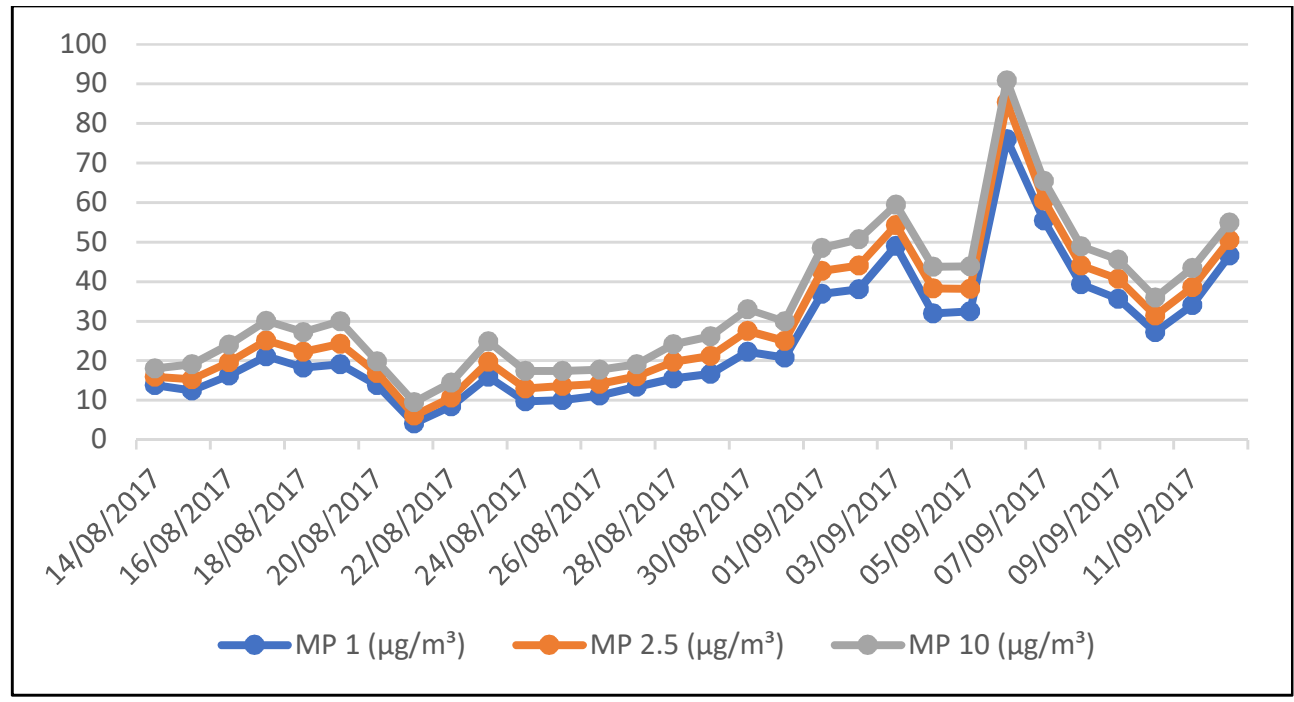

Figura 6: Média diária de materiais particulados (MP1, MP2.5, MP10) em Rondonópolis - MT no período de 14 de agosto a 12 de setembro de 2017.

\section{Análise estatística dos dados}

Ao considerar a utilização de múltiplas variáveis iniciou-se a aplicação estatística para a análise dos dados. Inicialmente realizou-se a estatística descritiva das variáveis em estudo, em seguida foi realizado o Teste de Anderson-Darling, que é um teste estatístico utilizado para verificar a normalidade das variáveis em estudo, como pode ser observado na Tabela 1. Considerando a correlação das variáveis relacionadas da poluição com as variáveis climáticas, utilizou-se a correlação de Kendall, tendo em vista que não foi possível aplicar a correlação de Pearson devido à ausência de normalidade na maioria das variáveis e que elas são medidas ao longo do tempo.

Pode-se observar que apenas as variáveis relacionadas a variável vento $\left(\mathrm{MP}_{1} 1,046\right.$ valor-p 0,388; $\mathrm{MP}_{2,5}$ 0,935 valor-p 0,388; $\mathrm{MP}_{10} 0,826$ valor-p 0,472) segue um comportamento normal $(p>0,05)$ em correlação com o teste de Anderson-Darling. O restante das variáveis não segue uma distribuição normal $(p<0,05)$, temperatura instante (MP1 1,046 valor-p 0,016; MP2,5 0,935 valor-p 0,013; MP10 0,826 valor-p 0,020), temperatura máxima (MP1 1,046 valor-p 0,008; MP2,5 0,935 valor-p 0,005; MP10 0,826 valor-p 0,008), temperatura mínima (MP1 1,046 valor-p 0,026; MP2,5 0,935 valor-p 0,017; MP10 0,826 valor-p 0,026) e umidade instante, máxima e mínima obtendo resultado similar (MP1 1,046 valor-p <0,001; MP2,5 0,935 
valor-p <0,001; MP10 0,826 valor-p <0,001), correlacionando o teste de Anderson-Darling com o teste de Kendall.

Tabela 1: Cálculo da média, variância, desvio padrão, assimetria, curtose, teste de Anderson-Darling e valores mínimos e máximos das variáveis em estudo. Rondonópolis (MT), 2017.

\begin{tabular}{|c|c|c|c|c|c|c|c|c|c|c|c|}
\hline \multirow{2}{*}{ Descrição } & \multirow{2}{*}{$\begin{array}{c}\text { PM1 } \\
\left(\mu \mathrm{g} / \mathrm{m}^{3}\right)\end{array}$} & \multirow{2}{*}{$\begin{array}{c}\text { PM2.5 } \\
\left(\mu \mathrm{g} / \mathrm{m}^{3}\right)\end{array}$} & \multirow{2}{*}{$\begin{array}{c}\text { PM10 } \\
\left(\mu \mathrm{g} / \mathrm{m}^{3}\right)\end{array}$} & \multicolumn{3}{|c|}{ Temperatura $\left({ }^{\circ} \mathrm{C}\right)$} & \multicolumn{3}{|c|}{ Umidade (\%) } & \multirow{2}{*}{ 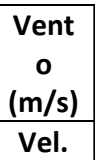 } & \multirow{2}{*}{$\begin{array}{c}\text { Chuv } \\
\text { a }\end{array}$} \\
\hline & & & & Inst. & Máx. & Mín. & Inst. & Máx. & Mín. & & \\
\hline Mínimo & 4,17 & 6,16 & 9,49 & $\begin{array}{c}22,4 \\
0\end{array}$ & $\begin{array}{c}22,7 \\
5\end{array}$ & $\begin{array}{c}22,0 \\
4\end{array}$ & 32,83 & 36,54 & 29,67 & 0,60 & 0,00 \\
\hline Máximo & 76,01 & 85,41 & 90,90 & $\begin{array}{c}30,4 \\
9\end{array}$ & $\begin{array}{c}31,4 \\
9\end{array}$ & $\begin{array}{c}29,4 \\
6\end{array}$ & 81,17 & 83,21 & 80,13 & 2,00 & 1,58 \\
\hline 10 Quantil & 13,84 & 16,22 & 19,32 & $\begin{array}{c}26,8 \\
2\end{array}$ & $\begin{array}{c}27,8 \\
2\end{array}$ & $\begin{array}{c}25,8 \\
4\end{array}$ & 39,40 & 43,60 & 35,62 & 1,02 & 0,00 \\
\hline 3ㅇ Quantil & 35,26 & 40,14 & 45,10 & $\begin{array}{c}28,5 \\
9\end{array}$ & $\begin{array}{c}29,6 \\
1\end{array}$ & $\begin{array}{c}27,5 \\
5\end{array}$ & 53,99 & 57,18 & 51,24 & 1,60 & 0,00 \\
\hline Média & 25,52 & 29,84 & 34,45 & $\begin{array}{c}27,5 \\
6\end{array}$ & $\begin{array}{c}28,4 \\
8\end{array}$ & $\begin{array}{c}26,6 \\
5\end{array}$ & 48,32 & 51,95 & 44,93 & 1,33 & 0,08 \\
\hline Mediana & 19,95 & 24,64 & 29,93 & $\begin{array}{c}27,6 \\
6\end{array}$ & $\begin{array}{c}28,5 \\
9\end{array}$ & $\begin{array}{c}26,7 \\
3\end{array}$ & 44,50 & 47,94 & 41,19 & 1,40 & 0,00 \\
\hline Variância & 266,45 & 309,27 & 329,80 & 3,30 & 3,82 & 2,95 & $\begin{array}{c}163,7 \\
7\end{array}$ & $\begin{array}{c}156,3 \\
0\end{array}$ & $\begin{array}{c}173,5 \\
2\end{array}$ & 0,11 & 0,09 \\
\hline Desvio Padrão & 16,32 & 17,59 & 18,16 & 1,82 & 1,95 & 1,72 & 12,80 & 12,50 & 13,17 & 0,34 & 0,30 \\
\hline Assimetria & 1,15 & 1,14 & 1,06 & $-0,69$ & $-0,82$ & $-0,54$ & 1,09 & 1,08 & 1,09 & $-0,32$ & 4,30 \\
\hline Curtose & 0,98 & 1,17 & 0,95 & 0,53 & 0,78 & 0,16 & 0,23 & 0,25 & 0,27 & $-0,66$ & 18,27 \\
\hline $\begin{array}{l}\text { Anderson- } \\
\text { Darling }\end{array}$ & 1,046 & 0,935 & 0,826 & $\begin{array}{c}0,49 \\
1\end{array}$ & $\begin{array}{c}0,56 \\
7\end{array}$ & $\begin{array}{c}0,35 \\
9\end{array}$ & 1,431 & 1,379 & 1,400 & 0,497 & 9,160 \\
\hline
\end{tabular}

A identificação de tendências climáticas por meio do teste de Kendall, pode ser um instrumento valioso para possíveis tomadas de decisões quanto às estratégias relacionadas aos impactos ambientais (FANTOLAN et al., 2012), no caso deste estudo, a correlação destas variáveis com a poluição atmosférica obtida pela concentração diária de material particulado $\left(\mathrm{MP}_{1}, \mathrm{MP}_{2,5}\right.$ e $\left.\mathrm{MP}_{10}\right)$.

Tabela 2: Aplicação da correlação de Kendall nas variáveis de poluição relacionadas com as variáveis climáticas.

\begin{tabular}{|c|c|c|c|c|c|c|c|c|c|}
\hline \multirow{2}{*}{ Variáveis } & \multicolumn{3}{|c|}{ MP 1 } & \multicolumn{3}{c|}{ MP 2,5 } & \multicolumn{3}{c|}{ MP 10 } \\
\cline { 2 - 11 } & Estatística z & Valor-p & $\rho$ & Estatística z & Valor- $\mathrm{p}$ & $\rho$ & Estatística z & Valor-p & $\mathrm{P}$ \\
\hline Temperatura instante & 2,391 & 0,016 & 0,308 & 2,462 & 0,013 & 0,317 & 2,319 & 0,020 & 0,299 \\
\hline Temperatura máxima & 291 & 0,008 & 0,337 & 295 & 0,005 & 0,356 & 291 & 0,008 & 0,337 \\
\hline Temperatura mínima & 280 & 0,026 & 0,287 & 284 & 0,017 & 0,305 & 280 & 0,026 & 0,287 \\
\hline Umidade instante & 102 & $<0,001$ & $-0,531$ & 100 & $<0,001$ & $-0,540$ & 100 & $<0,001$ & $-0,540$ \\
\hline Umidade máxima & 104 & $<0,001$ & $-0,521$ & 102 & $<0,001$ & $-0,531$ & 104 & $<0,001$ & $-0,521$ \\
\hline Umidade mínima & 101 & $<0,001$ & $-0,535$ & 99 & $<0,001$ & $-0,544$ & 99 & $<0,001$ & $-0,544$ \\
\hline Velocidade do vento & $-0,862$ & 0,388 & $-0,113$ & $-0,862$ & 0,388 & $-0,113$ & $-0,718$ & 0,472 & $-0,094$ \\
\hline Precipitação & $-2,066$ & 0,038 & $-0,310$ & $-2,066$ & 0,038 & $-0,310$ & $-2,066$ & 0,038 & $-0,310$ \\
\hline
\end{tabular}

Ao analisar a tabela 2, que descreve a aplicação da correlação das variáveis climáticas e de poluição atmosférica utilizando o teste de Kendall, infere-se que a variável velocidade do vento apresenta rejeição da hipótese de correlação em função das variáveis de poluição atmosférica $\left(\mathrm{MP}_{1}, \mathrm{MP}_{2,5}\right.$ e $\left.\mathrm{MP}_{10}\right)$ o que demonstra que esta variável não tem significância estatística. 


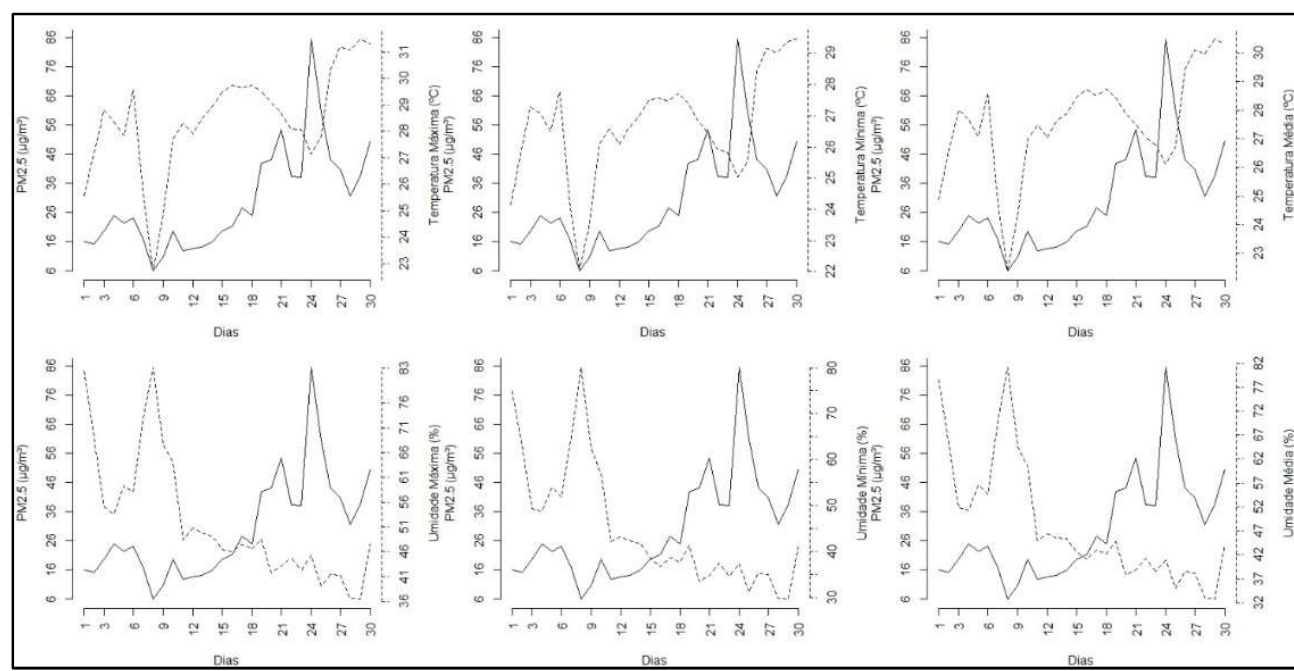

Figura 7: Comportamento da variável de poluição atmosférica (PM1) com relação as variáveis climáticas (temperatura e umidade).

As variáveis climáticas temperatura instante, temperatura máxima e temperatura mínima, obtiveram correlação estatisticamente significativa, pelo teste de Kendall, em função das variáveis de poluição atmosférica $\left(\mathrm{MP}_{1}, \mathrm{MP}_{2,5}\right.$ e $\left.\mathrm{MP}_{10}\right)$, possibilitando a interpretação de que com o concomitante aumento da temperatura ocorreu o aumento da poluição atmosférica $\left(\mathrm{MP}_{1}, \mathrm{MP}_{2,5}\right.$ e $\left.\mathrm{MP}_{10}\right)$ representado na Figura 7 , figura 8 e figura 9, assim como com a diminuição da temperatura ocorreu a diminuição do material particulado $\left(\mathrm{MP}_{1}, \mathrm{MP}_{2,5}\right.$ e $\left.\mathrm{MP} \mathrm{P}_{10}\right)$, figura 7, figura 8 e figura 9.



Figura 8: Comportamento da variável de poluição atmosférica (PM2,5) com relação as variáveis climáticas (temperatura e umidade).

De acordo com Zhao et al. (2013), o aumento da temperatura especialmente durante o verão, pode conduzir a uma intensa dispersão vertical de poluentes os quais induzem a uma relação inversa entre temperatura e MP, especialmente no caso de partículas finas como o $\mathrm{MP}_{1,0}$ e $\mathrm{MP}_{2,5}$. Nessa perspectiva, denominamos a figura 9 'Comportamento da variável de poluição atmosférica (PM10) com relação as variáveis climáticas (temperatura e umidade)'. 


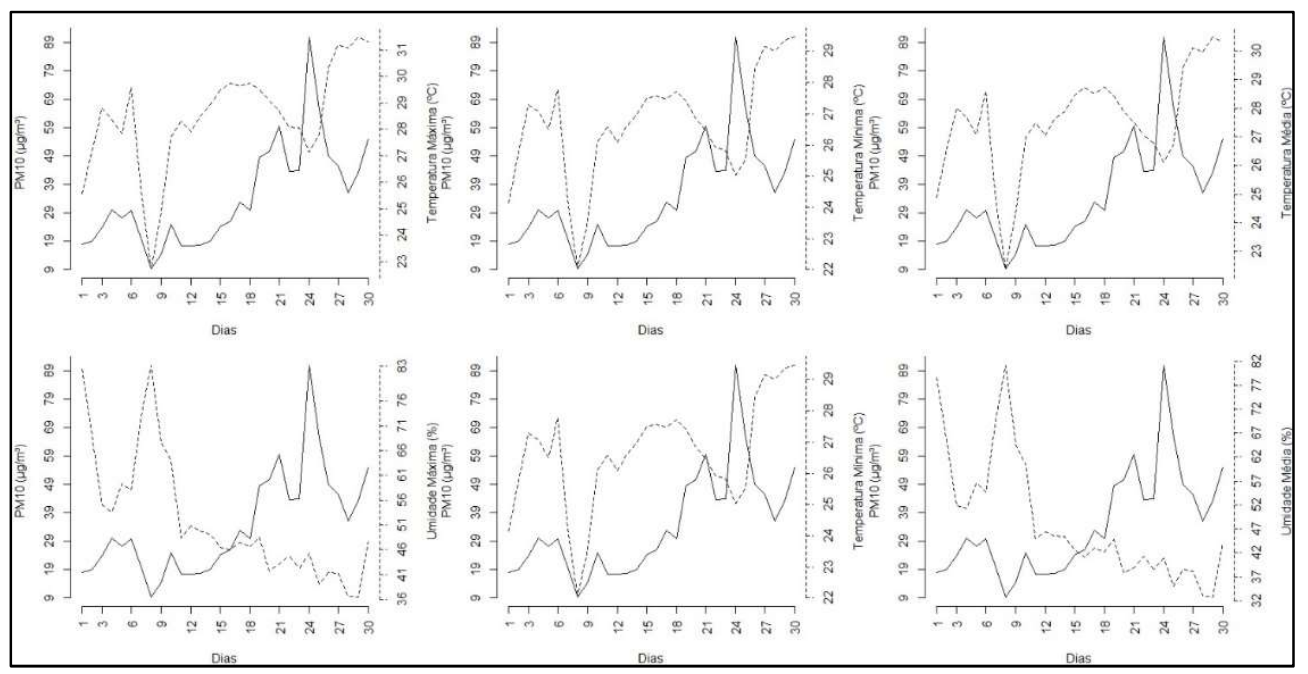

Figura 9: Comportamento da variável de poluição atmosférica (PM10) com relação as variáveis climáticas (temperatura e umidade).

Há evidência da relação inversa apresentada pelo teste de Kendall, o que corrobora com a característica do bioma do Cerrado no período do estudo, pois conforme Torres (2006), o aumento de focos de calor na estação seca foi devido à baixa umidade relativa do ar causada pela ausência de chuvas ou baixo índice pluviométrico o que provoca aumento no déficit de pressão de vapor da atmosfera e no poder evaporativo dos vegetais, tornando-os mais secos. Machado et al. (2014), por meio de seu estudo no município de Cuiabá (MT), no período de seca (abril a setembro), indicaram o maior número de queimadas e de focos de calor apontando maior concentração de material particulado em suspensão na atmosfera.

As condições climáticas e incêndios mantêm uma estreita relação, desde a probabilidade de ocorrências de incêndios decorrente das condições atmosféricas em um dado período, até a manutenção e propagação do fogo (TORRES, 2006). Ainda em discussão sobre a análise da tabela 2, observa-se a correlação negativa entre a umidade instante, umidade máxima e umidade mínima juntamente com a precipitação em função da poluição atmosférica $\left(\mathrm{MP}_{1}, \mathrm{MP}_{2,5}\right.$ e $\left.\mathrm{MP}_{10}\right)$, em que a análise de correlação de Kendall alcança significância estatística por meio da interpretação das variáveis serem inversamente proporcionais, ou seja, com o aumento da umidade e na presença de precipitação a poluição atmosférica $\left(\mathrm{MP}_{1}, \mathrm{MP}_{2,5}\right.$ e $\left.\mathrm{MP}_{10}\right)$ sofre declínio, representado na figura 7, figura 8, figura 9 a correlação entre o material particulado e a umidade e na figura 10 a correlação entre o material particulado e a precipitação.



Figura 10: Comportamento das variáveis de poluição atmosférica $\left(\mathrm{MP}_{1}, \mathrm{MP}_{2,5}\right.$ e $\left.M \mathrm{P}_{10}\right)$ com relação a variável meteorológica (precipitação). 
Guerra et al (2011) analisou a concentração do poluente $\mathrm{MP}_{2,5}$ em função das variáveis meteorológicas (umidade e precipitação) obtendo a mesma relação inversa, conforme há um maior volume precipitado, a concentração do poluente diminui de forma efetiva. As chuvas fazem com que a atmosfera seja lavada carregando os poluentes, efeito washout e rainout (GUERRA et al., 2011). A mesma evidência foi destacada por Li et al. (2015) demonstrando que a precipitação tem um grande impacto sobre as concentrações de material particulado e, principalmente, diminuem as partículas maiores ( $\left.\mathrm{MP}_{10}\right)$, exercendo pouca influência sobre as partículas finas $\left(\mathrm{MP}_{2,5}\right)$.

Desta forma, foi utilizado o método estatístico de regressão linear múltiplo para as variáveis dependentes da poluição atmosférica $\left(\mathrm{MP}_{1}, \mathrm{MP}_{2,5}\right.$ e $\left.\mathrm{MP}_{10}\right)$ em relação as variáveis climáticas (temperatura máxima, temperatura mínima, umidade instante e umidade máxima) as outras variáveis (temperatura instante, umidade mínima, precipitação e velocidade do vento) foram excluídas do método por apresentarem um valor-p >0,05, não demonstrando significância estatística, assim, foram abordados somente as variáveis que apresentaram o $p$ valor $<0,05$, conforme descrito na tabela 3 .

Tabela 3. Ajuste dos modelos de regressão Gamma para as variáveis dependentes de poluição $\left(\mathrm{MP}_{1}, \mathrm{MP}_{2,5}\right.$ e $\left.M P_{10}\right)$ em relação as variáveis climáticas.

\begin{tabular}{|c|c|c|c|c|c|c|c|c|c|c|c|c|}
\hline \multirow{2}{*}{ Coeficientes } & \multicolumn{3}{|c|}{ Estimativa } & \multicolumn{3}{|c|}{ Erro Padrão } & \multicolumn{3}{|c|}{ Estatística-t } & \multicolumn{3}{|c|}{ Valor-p } \\
\hline & $\mathrm{MP}_{1}$ & $\mathrm{MP}_{2,5}$ & $\mathrm{MP}_{10}$ & $\mathrm{MP}_{1}$ & $\mathrm{MP}_{2,5}$ & $\mathrm{MP}_{10}$ & $\mathrm{MP}_{1}$ & $\mathrm{MP}_{2,5}$ & $\mathrm{MP}_{10}$ & $\mathrm{MP}_{1}$ & $\mathrm{MP}_{2,5}$ & $M P_{10}$ \\
\hline $\begin{array}{c}\boldsymbol{\beta 0} \\
\text { (Temperatura } \\
\text { máxima) }\end{array}$ & 2,255 & 1,989 & 1,678 & 0,545 & 0,473 & 0,412 & 4,139 & 4,198 & 4,072 & 0,0003 & 0,0003 & 0,0004 \\
\hline $\begin{array}{c}\boldsymbol{\beta 1} \\
\text { (Temperatura } \\
\text { mínima) }\end{array}$ & $\begin{array}{c}- \\
2,179\end{array}$ & $\begin{array}{c}- \\
1,926\end{array}$ & $\begin{array}{c}- \\
1,632\end{array}$ & 0,540 & 0,470 & 0,408 & $\begin{array}{c}- \\
4,031\end{array}$ & 4,099 & $\begin{array}{c}- \\
3,992\end{array}$ & 0,0004 & 0,0004 & 0,0005 \\
\hline $\begin{array}{c}\mathbf{\beta 2} \\
\text { (Umidade instante) }\end{array}$ & 0,622 & 0,549 & 0,48 & 0,177 & 0,154 & 0,134 & 3,513 & 3,563 & 3,580 & 0,0017 & 0,0015 & 0,0015 \\
\hline $\begin{array}{c}\boldsymbol{\beta 3} \\
\text { (Umidade máxima) }\end{array}$ & $\begin{array}{c}- \\
0,605 \\
\end{array}$ & $\begin{array}{c}- \\
0,535 \\
\end{array}$ & $\begin{array}{c}- \\
0,471 \\
\end{array}$ & 0,170 & 0,148 & 0,128 & $\begin{array}{c}- \\
3,550 \\
\end{array}$ & $\begin{array}{c}- \\
3,614 \\
\end{array}$ & $\begin{array}{c}- \\
3,655 \\
\end{array}$ & 0,0016 & 0,0013 & 0,0012 \\
\hline
\end{tabular}

Utilizou-se o modelo de regressão linear múltipla com distribuição Gamma, ilustrado na figura 11, possibilitando a interpretação, por meio da análise dos gráficos, que não há indícios de afastamentos sérios da suposição de distribuição gama para as variáveis dependentes de poluição atmosférica $\left(\mathrm{MP}_{1}, \mathrm{MP}_{2,5} \mathrm{e}\right.$ $\mathrm{MP}_{10}$ ), bem como para a suposição de homogeneidade do coeficiente de variação para as variáveis climáticas (temperatura máxima, temperatura mínima, umidade instante e umidade máxima).
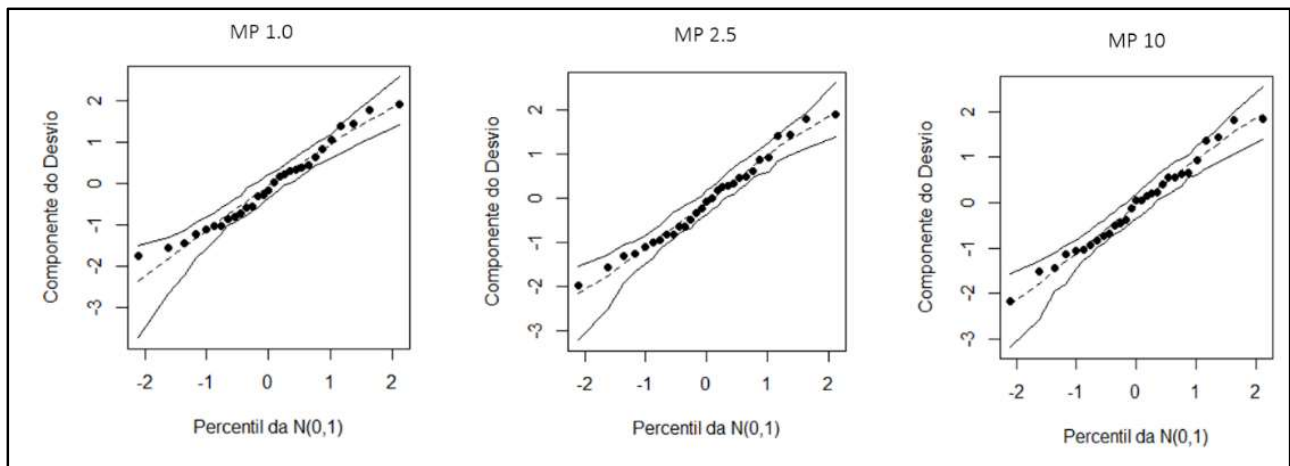

Figura 11: Gráficos de resíduos do modelo de regressão Gamma para as variáveis da poluição atmosférica $\left(M P_{1}, M P_{2,5}\right.$, $\mathrm{MP}_{10}$ ) em função das variáveis climáticas (temperatura máxima, temperatura mínima, umidade instante e umidade máxima). 
Este modelo permite interpretar o fenômeno por meio do ajuste dos dados, pois os resíduos estão corroborando para isto. Portanto, à medida que aumenta uma unidade na temperatura máxima obtêm-se uma redução de $45 \%$ na poluição atmosférica. Diante do exposto, considera-se existir uma correlação linear entre as variáveis climáticas e a poluição atmosférica, de maneira que outros autores também compartilham deste resultado.

Tai et al. (2010) que aplicaram o modelo de regressão linear múltipla para estudar as correlações de $\mathrm{MP}_{2,5}$ com variáveis meteorológicas utilizando um registro observacional de 11 anos (1998-2008) sobre o Estados Unidos obtendo correlações com temperatura, umidade relativa e direção do vento para diferentes componentes individuais e regionais de $\mathrm{MP}_{2,5}$. Tai et al. (2010) aponta para a importância de representar adequadamente a dependência de temperatura de emissões agrícolas, biogênicas e de incêndios florestais (TAl et al., 2010).

\section{CONCLUSÕES}

O período de estudo, meses de agosto e setembro, refletem criticamente sobre a ocorrência da queima de biomassa no Centro-Oeste brasileiro, corroborando com Abreu et al. (2016), que destacou o mês de setembro com a maior ocorrência de queimadas, representando $42,6 \%$ da amostra pesquisada, na região leste de Mato Grosso. Somado a esta característica as variáveis climáticas, temperatura, umidade relativa do ar e precipitação exercem influência nas concentrações de material particulado $\left(M_{1}, M_{2,5}\right.$ e $\left.M P_{10}\right)$ veiculados na atmosfera no município de Rondonópolis, região sul de Mato Grosso.

As queimadas têm sido uma preocupação constante no período da seca, quando parte dos danos no ecossistema chegam a ser sentidos quase que na totalidade dos municípios integrantes do estado de Mato Grosso, que ficam cobertos de fumaças (SANTIAGO, 2013), e refletem vários problemas de saúde nas comunidades habitadas, como por exemplo, mal estar, dor de cabeça, intoxicação pulmonar, tosses e dificuldade para respirar.

Em Rondonópolis, os níveis de poluentes, no período de queimada, atingiram índices críticos, apresentando concentrações acima do estabelecido pela WHO (2016), o que afeta diretamente a saúde e o bem-estar da população, facilitando o agravamento dos casos de problemas respiratórios, principalmente de infecções das vias aéreas inferiores, devido à má qualidade do ar.

Salienta-se como limitação do estudo o período referente a coleta dos dados, 30 dias, podendo limitar a capacidade de análise do fenômeno, possibilitando estudos futuros e com maior abrangência temporal de dados. Espera-se que os resultados apresentados possam contribuir para um melhor entendimento do impacto da poluição atmosférica relacionada a variáveis climáticas e as queimadas no município de Rondonópolis (MT).

\section{REFERÊNCIAS}

ABREU, F. A.; SOUZA, J. S. A.. Dinâmica espaço-temporal de focos de calor em duas terras indígenas do estado de Mato Grosso: uma abordagem geoespacial sobre a dinâmica do uso do fogo por Xavantes e Bororos. Floresta e Ambiente, v.23, n.1, p.1-10, 2016. DOI: http://doi.org/10.1590/21798087.041813 
ARBEX, M. A.; CANÇADO, J. E. D.; PEREIRA, L. A. A.; BRAGA, A. L. F.; SALDIVA, P. H. N.. Queima de biomassas e efeito sobre a saúde. Jornal Brasileiro de Pneumologia, v.30, n.2, p.158-175, 2004. DOI: http://doi.org/10.1590/S1806$\underline{37132004000200015}$

CARNESECA, E. C.; ACHCAR, J. A.; MARTINEZ, E. Z. Association between particulate matter air pollution and monthly inhalation and nebulization procedures in Ribeirão Preto, São Paulo State, Brazil. Cadernos de Saúde Pública, Rio de Janeiro, v.28, n.8, p.1591-1598, 2012.

CONAMA. Conselho Nacional do Meio Ambiente. Resolução número 003 de 28 de junho de 1990. Dispõe sobre padrões de qualidade do ar, previstos no PRONAR. Brasília: DOU, 1990.

FONTOLAN, M. R.; FERREIRA, D. H. L.; PENEREIRO, J. C. Comportamento climático ao longo do rio tietê: aplicações envolvendo testes estatísticos. Revista Geonorte, v.1, n.5, p.466-475, 2012.

GUERRA, F. P.; MIRANDA, R. M.. Influência da meteorologia na concentração do poluente atmosférico $P M 2,5$ na RMRJ e na RMSP. In: CONGRESSO BRASILEIRO DE GESTÃO AMBIENTAL, 2. Anais. Londrina: 2011.

IGNOTTI, E.; HACON, S. S.; SILVA, A. M. C.; JUNGER, W. L.; CASTRO, H.. Efeitos das queimadas na Amazônia: método de seleção dos municípios segundo indicadores de saúde. Revista Brasileira de Epidemiologia, v.10, n.4, p.453-464, 2007.

JALLAD, F.; KATHEERI E.; OMAR, M.. Levels of particulate matter in Western UAE impacts: a meta-analysis. BMC Public Health, v.7, n.89, p.89-100, 2013.

LI, H.; GUO, B.; HAN, M.; TIAN, M.; ZHANG, J.. Particulate Matters Pollution Characteristic and the Correlation between PM (PM2.5, PM10) and Meteorological Factors during the Summer in Shijiazhuang. Journal of Environmental Protection, v.6, p.457-463, 2015. DOI: http://doi.org/10.4236/jep.2015.65044

LI, W. J.; SHAO, L. Y.; BUSECK, P. R.. Haze types in Beijing and the influence of agricultural biomass burning. Atmospheric Chemistry and Physics, v.10, n.1, p.8119-8130, 2010. DOI: http://doi.org/10.5194/acp-10-8119-2010

MACHADO, N. G.; SILVA, F. C. P.; BIUDES, M. S.. Efeito das condições meteorológicas sobre o risco de incêndio e o número de queimadas urbanas e focos de calor em CuiabáMT, Brasil. Ciência e Natura, v.36, 2014. DOI:

http://doi.org/10.5902/2179460X11892

MELO, M. M.. A confluência entre a ecologia do fogo e o conhecimento Xavante sobre o manejo do fogo no Cerrado. Tese (Doutorado em Desenvolvimento Sustentável) Universidade de Brasília, Brasília, 2007.

PRADA, M.; MARINHO-FILHO, J.. Effects of fire on the abundance of Xenarthrans in Mato Grosso, Brazil. Austral Ecology, v.29, n.5, p.568-573, 2004.
RIBEIRO, H.; ASSUNÇÃO, J. V.. Efeitos das queimadas na saúde humana. Estudos Avançados, v.16, n.44, p.125-148, 2002. DOI: http://doi.org/10.1590/S010340142002000100008

ROCHA, J. C.; ROSA, A. H.; CARDOSO, A. A.. Introdução à química ambiental. Porto Alegre: Bookman, 2004.

SALDIVA, P. H. N.. Emissões de Poluentes Atmosféricos por Fontes Móveis e Estimativa dos Efeitos em Saúde em 6 Regiões Metropolitanas Brasileiras. São Paulo: LAPAE, 2007.

SALGADO, P. E. T.. Informações Gerais e Ecotoxicológicas de Material Particulado. Salvador: Centro de Recursos Ambientais, 2003.

SANTIAGO, A.. Material particulado total suspenso na baixa atmosfera em Cuiabá-MT no período de queimadas. Dissertação (Mestrado em Engenharia de Edificações e Ambiental) - Universidade Federal de Mato Grosso, Cuiabá, 2013.

SILVA, E. B. F.; TELES, L. J. S.; SANTOS, L. A. N.. Ocorrências de focos de calor no estado de Rondônia em 2007. Sociedade \& Natureza, v.21, n.2, p.123-140, 2009.

SILVERMAN, B. W.. Density Estimation for Statistics and Data Analysis. Nova York: Chapman and Hall, 1986.

TAI, A. P. K.; MICKLEY, L. J.; JACOB, D. J.. Correlations between fine particulate matter (PM2.5) and meteorological variables in the United States: Implications for the sensitivity of PM2.5 to climate change. Atmospheric Environment, v.44, p.3976-3984, 2010. DOI: http://doi.org/10.1016/j.atmosenv.2010.06.060

TORRES, F. T. P.. Relações entre fatores climáticos e ocorrências de incêndios florestais na cidade de Juiz de Fora (MG). Caminhos de Geografia, v.7, n.18, p.162-171, 2006.

VELLOSO, M. F. A.. Avaliação de modelos gaussianos para fins regulatórios: um estudo para a bacia aérea III da região metropolitana do Rio de Janeiro. Dissertação (Mestrado em Engenharia Mecânica) - Universidade Federal do Rio de Janeiro, Rio de Janeiro, 2007.

WHO. World Health Organization. Ambient air pollution: a global assessment of expousure and burden of disease. Geneva: WHO, 2016.

ZHAO, H.; CHE, H.; ZHANG, X.; MA, Y.; WANG, Y.; WANG, H.; WANG, Y.. Characteristics of visibility and particulate matter (PM) in an urban area of Northeast China. Atmospheric Pollution Research, v.4, n.1, p.427-434, 2013. DOI: http://doi.org/10.5094/APR.2013.049

ZHOU, Y.; LEVY, J. I.. Factors influencing the spatial extent of mobile source air pollution desert and factors affecting their distribution. WIT Transactions on Ecology and the Environment, v.174, p.111-122, 2007.

A CBPC - Companhia Brasileira de Produção Científica (CNPJ: 11.221.422/0001-03) detém os direitos materiais desta publicação. Os direitos referem-se à publicação do trabalho em qualquer parte do mundo, incluindo os direitos às renovações, expansões e disseminações da contribuição, bem como outros direitos subsidiários. Todos os trabalhos publicados eletronicamente poderão posteriormente ser publicados em coletâneas impressas sob coordenação da Sustenere Publishing, da Companhia Brasileira de Produção Científica e seus parceiros autorizados. Os (as) autores (as) preservam os direitos autorais, mas não têm permissão para a publicação da contribuição em outro meio, impresso ou digital, em português ou em tradução. 